\author{
Sarah Barriage \\ University of Kentucky, Lexington, Kentucky, USA \\ Vanessa Kitzie \\ University of South Carolina, Columbia, South Carolina, USA
}

Diana Floegel

Rutgers, The State University of New Jersey, New Brunswick, New Jersey, USA

Shannon Oltmann

University of Kentucky, Lexington, Kentucky, USA

\title{
"It's hard to see how these would be harmful to kids": Public library staff perceptions of child development and drag queen storytimes (Paper)
}

\begin{abstract}
:
This paper reports preliminary results of a survey of 458 public library staff members regarding their perceptions of drag queen storytimes (DQS) and the ways in which these storytimes influence child development. The majority of respondents from libraries that have hosted at least one DQS agreed that DQS support healthy child development and positively influence children's understanding of gender and/or sexuality, while respondents from libraries that have not hosted DQS were more likely to disagree or report being undecided. Specific ways in which respondents perceive DQS to influence child development are also analyzed.
\end{abstract}

\section{Introduction}

With the founding of Drag Queen Story Hour in 2015 (https://www.dragqueenstoryhour.org/), drag queen storytimes (DQS) have become an increasingly popular program in public libraries. Featuring drag performers reading books, singing songs, and leading other activities in otherwise typical storytime settings, these events have proven to be highly controversial. Newspaper headlines across the world reflect the varying levels of support and/or opposition that DQS evoke in various communities (e.g., Bui, 2018; Knox, 2019; Peet \& Yorio, 2018; Pereira, 2019; Taylor, 2020).

Because DQS are typically planned and advertised as events for children, such headlines and accompanying content often focus on how these storytimes intersect with popular ideas and theories about child development. Supporters of DQS argue that these events can teach young children acceptance and celebration of diversity, providing positive representations of underrepresented identities (Proxmire, 2018; Staino, 2017). Detractors of DQS believe that these events expose children to sexualized content (Charlton, 2018; Stickles, 2018), promote 
homosexuality (Landgraf, 2018; Stickles, 2018), and confuse children's understanding of gender (Bui, 2018).

Although DQS continue to be featured in the popular press, little scholarly work has examined these events generally (for exceptions, see Montague \& Latham, 2019; Naidoo, 2018) or how such events intersect with practitioners' conceptualizations of child development specifically.

\section{Research Questions}

The overall aim of this study was to explore public library staff experiences with and attitudes toward DQS. The specific research question addressed in this paper is: What perceptions do public library staff members have about the relationship between DQS and child development?

\section{Methods}

A survey was developed to capture library staff experiences with and perceptions of DQS. Data were collected via Qualtrics, an online survey tool. Participants were recruited by email invitations sent to children's librarians and library directors in each US state, as well as US-based professional and institutional listservs.

The authors imported Qualtrics data into Excel and generated pivot tables summing responses across question categories for closed-response questions. Authors also calculated post-hoc twoproportion z-tests $(\alpha=0.05)$ to test for significant differences between population proportions among respondents from institutions that have hosted DQS and those from institutions that have not hosted DQS. The Benjamini-Hochberg procedure (Benjamini and Hochberg, 1995) was applied to p-values prior to significance testing to adjust for false-discovery rates. Effect sizes were determined using Cohen's h (Cohen 1988), which measures differences between two proportions. Qualitative responses to open-ended survey questions were analyzed using the constant comparative method (Charmaz 2014).

Four hundred and fifty-eight library staff members responded to the survey. The majority of respondents work at a library that has not hosted a DQS in the past $(n=341,74 \%)$, and the remaining 117 respondents (26\%) work at a library that has hosted at least one DQS. Most respondents reported being in a position to make programming decisions for their library $(\mathrm{n}=$ $387,84 \%)$. Almost three-quarters of participants reported having very liberal $(\mathrm{n}=211,45 \%)$ and liberal $(\mathrm{n}=124,27 \%)$ personal political views.

\section{Findings}

The majority of respondents strongly agreed that DQS positively influences children's understanding of gender and/or sexuality $(\mathrm{n}=211,46 \%)$ and supports healthy child development $(\mathrm{n}=199,44 \%)$; however, there were small to moderate differences between respondents who work at libraries that had and had not hosted a DQS (see Tables 1-2). Specifically, there was a moderate difference between respondents from libraries who had hosted DQS who strongly agreed that DQS positively influences children's understanding of gender and/or sexuality $\left(\mathrm{n}_{1}=\right.$ $83,72 \%)$ and supports healthy child development $\left(\mathrm{n}_{2}=82,71 \%\right)$ as compared to respondents from libraries that had not hosted DQS $\left(\mathrm{n}_{1}=128,38 \% ; \mathrm{n}_{2}=117,35 \%\right)$. Respondents from 
libraries that had not hosted DQS instead had a slightly higher likelihood of either disagreeing, strongly disagreeing, or exhibiting indecision with both statements.

Table 1. From your perspective, do you think drag queen storytimes positively influence children's understanding of gender and/or sexuality?

\begin{tabular}{|c|c|c|c|c|c|c|c|c|}
\hline & \multicolumn{2}{|c|}{ Hosted } & \multicolumn{2}{|c|}{ Not hosted } & \multirow[t]{2}{*}{ sig. } & \multirow[t]{2}{*}{$\mathrm{h}$} & \multicolumn{2}{|c|}{ Total } \\
\hline & $\mathrm{n}$ & $\%$ & $\mathrm{n}$ & $\%$ & & & $\mathrm{n}$ & $\%$ \\
\hline Strongly agree & 83 & $72 \%$ & 128 & $38 \%$ & $* * *$ & 0.7 & 211 & $46 \%$ \\
\hline Agree & 21 & $18 \%$ & 83 & $25 \%$ & & & 104 & $23 \%$ \\
\hline Disagree & 3 & $3 \%$ & 28 & $8 \%$ & $*$ & 0.3 & 31 & $7 \%$ \\
\hline Strongly disagree & 4 & $3 \%$ & 46 & $14 \%$ & $* *$ & 0.4 & 50 & $11 \%$ \\
\hline Undecided & 5 & $4 \%$ & 53 & $16 \%$ & $* *$ & 0.4 & 58 & $13 \%$ \\
\hline Total & 116 & & 338 & & & & 454 & \\
\hline
\end{tabular}

Note: $<0.05(*),<0.01(* *)$, and $<0.001(* * *)$ 
Table 2. From your perspective, do you think drag queen storytimes support healthy child development?

\begin{tabular}{|c|c|c|c|c|c|c|c|c|}
\hline & \multicolumn{2}{|c|}{ Hosted } & \multicolumn{2}{|c|}{ Not hosted } & \multirow[t]{2}{*}{ sig. } & \multirow[t]{2}{*}{$\mathrm{h}$} & \multicolumn{2}{|c|}{ Total } \\
\hline & $\mathrm{n}$ & $\%$ & $\mathrm{n}$ & $\%$ & & & $\mathrm{n}$ & $\%$ \\
\hline Strongly agree & 82 & $71 \%$ & 117 & $35 \%$ & $* * *$ & 0.7 & 199 & $44 \%$ \\
\hline Agree & 25 & $22 \%$ & 96 & $28 \%$ & & & 121 & $27 \%$ \\
\hline Disagree & 2 & $2 \%$ & 28 & $8 \%$ & $*$ & 0.3 & 30 & $7 \%$ \\
\hline Strongly disagree & 4 & $3 \%$ & 43 & $13 \%$ & $* *$ & 0.4 & 47 & $10 \%$ \\
\hline Undecided & 3 & $3 \%$ & 54 & $16 \%$ & $* * *$ & 0.5 & 57 & $13 \%$ \\
\hline Total & 116 & & 335 & & & & 454 & \\
\hline
\end{tabular}

Note: $<0.05(*),<0.01(* *)$, and $<0.001(* * *)$

Respondents noted specific ways in which they perceive DQS as being in support of child development, including the potential for such events to impart lessons related to "acceptance," "tolerance," "empathy," "respect," "diversity," and "inclusion." Some respondents also noted the potential for DQS to "encourage self-acceptance and confidence" in children as well as "exploration of identity." In relation to gender specifically, one respondent noted that DQS "help deconstruct harmful gender norms and toxic masculinity," while another noted that "they broaden the minds of children and how they view identity and gender." Others perceive DQS as an opportunity to aid children in the development of their "social and emotional learning," including "social awareness and relationship skills."

For some respondents, DQS align with the literacy-related goals that typically drive storytime programming. For example, one respondent stated, "It is important for kids to see a variety of adults engage with books, so that they know books and stories are for everyone." Another stated that DQS "support child development by engaging children with print material and advancing language skills." 
Many respondents who articulated ways in which DQS support healthy child development responded to the question of how DQS might be harmful and/or inappropriate with responses such as "n/a," "none," and "zero ways." As one respondent stated, "It's hard to see how these would be harmful to kids in our demographic."

Conversely, those who voiced strong opinions on the ways in which DQS may be harmful often did not express how DQS might support child development. One respondent stated, "in no way does DQS support child development." Those who held negative views of DQS described these events as "confusing," "inappropriate," and "an attempt to normalize abnormal behavior." Several respondents objected to the perceived sexualized nature of drag performances, with one respondent stating: "It is harmful to push anything to do with sex or sexuality on young children."

A number of respondents noted that the age range of the typical storytime audience seemed to be incongruous with drag in general: "I think that it has been forgotten that the intent of drag was for adult entertainment. I don't know that it transfers well to child entertainment." Similarly, another respondent who attended a DQS event stated that the event "reinforced my thoughts that drag queen programming was more for the adults than the children."

Other respondents voiced concern about the impact of DQS on children who might be trans or gender non-conforming. While some respondents felt that DQS provide children with positive representations of queer individuals, others felt the potential of "conflating 'drag' with "transgender" to be problematic. The limitations of representing the LGBTQ+ community through DQS were explicated in this response:

I am most concerned about children who do not conform to stereotypical gender roles if a drag queen is the only role model they are offered. Why not ask some transgender community members to read a story and tell a bit about themselves? Heck, why not hire a transgender librarian?

Some respondents noted that while they do not believe that DQS "in and of themselves" are harmful to children, they do believe that the protests and associated discourse may negatively impact children. For example, one respondent stated: "I think the protests are more harmful. That children are able to see that much hate is not good." Relatedly, other respondents noted their concerns about children's safety at DQS events that attract protestors, as well as the level of preexisting knowledge and training received by participating drag queens in storytelling skills and early childhood education.

\section{Conclusion}

These findings suggest that respondents from institutions that have previously hosted a DQS hold a fairly solid conviction that these events contribute to healthy child development as compared to respondents from institutions that have not hosted a DQS, who express less conviction, as well as more disagreement and indecision. Further research concerning the ways in which such events impact children is needed, including work that centers the views of children and their parents, as well as work that further interrogates practitioner beliefs concerning child development. 


\section{Reference List:}

Benjamini, Y., \& Hochberg, Y. (1995). Controlling the false discovery rate: A practical and powerful approach to multiple testing. Journal of the Royal Statistical Society, Series B (Methodological), 57(1), 289-300.

Bui, C. (2018, August 21). Community split over New Jersey library's 'drag queen story hour' for children. CBS New York. Retrieved from https://newyork.cbslocal.com/2018/08/ 21/rahway-drag-queen-story-hour/

Charlton, J. (2018). Something for everyone at the world's libraries. Information Today, 35(3), 22.

Charmaz, K. (2014). Constructing grounded theory (2 $\left.2^{\text {nd }} \mathrm{ed}\right)$. London, England: Sage.

Cohen, J. (1988). Statistical power analysis for the behavioral sciences ( $2^{\text {nd }}$ ed). New York, NY: Academic Press.

Knox, J. (2019, November 18). Despite controversy, Kelowna library's Drag Queen Story Time grows in popularity. Retrieved from https://globalnews.ca/news/6179257/kelownalibrary-drag-queen-story-time-popularity/

Landgraf, G. (2018, November 1). Fierceness - and fierce opposition. American Libraries. Retrieved from https://americanlibrariesmagazine.org/2018/11/01/drag-queen-storytimesfierceness-fierce-opposition/

Montague, R.-A., \& Latham, J. (2019). Queer reflections: New views from library drag storytimes. Paper presented at IFLA World Library and Information Congress. Athens, Greece, August 24-30.

Naidoo, J. C. (2018). A rainbow of creativity: Exploring drag queen storytimes and gender creative programming in public libraries. Children \& Libraries, 16(4), 12-20.

Peet, L., \& Yorio, K. (2018). Louisiana drag story hour protests escalate. Library Journal, 143(17), 9-10.

Pereira, A. (2019, February 12). After protests, an estimated 500 attend East Bay library's 'drag queen story hour.' SFGate. Retrieved from https://www.sfgate.com/local/article/dragqueen-story-hour-brentwood-library-east-bay-13611760.php

Proxmire, C. (2017, December 20). Huntington Woods hosts Michigan's first drag queen story time, more to come. PrideSource. Retrieved from https://pridesource.com/article huntington-woods-hosts-michigans-first-drag-queen-story-time-more-to-come/

Staino, R. (2017). Storytime gets fabulous. School Library Journal, 63(7), 14.

Stickles, J. (2018). Sparking the ire, and the support, of a community: When a public library program becomes something more. Children \& Libraries, 16(4), 20-22.

Taylor, J. (2020, January 12). Drag queen storytime at Brisbane library disrupted by rightwing student group. Retrieved from https://www.theguardian.com/world/2020/jan/13/dragqueen-storytime-at-brisbane-library-disrupted-by-rightwing-student-group 